\title{
Accessibility to Electronic Resources by Students in Higher Learning Institutions in Mwanza City, Tanzania
}

\author{
Margreth James Mwamasso ${ }^{1}$ and Daniel Oduor Onyango ${ }^{2}$ \\ ${ }^{1}$ Librarian, Tanzania Institute of Accountancy, Mwanza, Tanzania \\ ${ }^{2}$ Department of Education Foundations, St. Augustine University of Tanzania
}

Correspondence: d.juma@yahoo.com; mwamasso@gmail.com

\begin{abstract}
This study sought to investigate the accessibility to electronic resources by students in higher learning institutions in Mwanza city. The study was guided by the Utilization Theory. The study employed mixed research approach and convergent parallel research design. The study sampled a total of 390 respondents comprising of 377 students, 8 lecturers, 4 librarians and 1 ICT expert. Stratified and simple random sampling techniques were used to select students and lecturers respectively while purposive sampling was used to select librarians and ICT experts. Questionnaire and interview guides were used to collect data. Statistical descriptions and themes were used to analyze quantitative and qualitative data respectively. The study found that the infrastructures for electronic learning resources and facilities like computer laboratories and internet infrastructures were not well established to allow students in higher learning institutions access electronic resources. It was further found that students faced challenges such as shortage of computers, electricity and network challenges in accessing electronic resources. It was also found that majority of the students were unable to use computers in accessing electronic stored resources due to lack of computer knowledge base as well as lack of financial capacity to secure electronic devices. Hence, it was concluded that most students in higher learning institutions are unable to access electronic resources due to lack of adequate infrastructure, shortage of computers, electricity and network challenges, lack of computer literacy and financial constraints. The study recommended that collective initiatives should be put in place to make sure that ICT subject is taught from primary schools to higher learning institutions, proper infrastructure are established and students are financially facilitated to enable them secure electronic devices in order to enhance accessibility to electronic resources in higher learning institutions.
\end{abstract}

Key words: Accessibility, Electronic Resources, Students, Higher Learning Institutions, Mwanza, Tanzania

\section{Introduction}

For a long time, studying and learning have been through normal physical libraries or sometimes referred to as "House of writing" which has been used as a deposition of learning materials which include collections of different books, journals, manuscripts, artifacts, magazines, newspapers and other materials (Nkebukwa, 2016).

From the middle of $20^{\text {th }}$ Century, the world has witnessed a huge change of life styles accompanied by innovations in science and technology. This has resulted into development of ICT which has changed the use of printed learning resources to electronic resources that are mostly used by students in higher learning institutions. The resources like e-books, electronic journals and articles are most useful in recent years by university students (Owolabi, Idowu, Okocha \& Ogundare, 2016).

Online learning was first initiated by University of Phoenix in 1989 by offering education programs through internet services. Later in 1998, various programs were offered by other Universities such as California Virtual University, Trident University, New York University and Western Governor's University (Tsakonas \& Papatheodorou, 2006).

12 East African Journal of Education and Social Sciences (EAJESS) 1(3)12-19 
The electronic learning materials started to be popular in modern world in 1990 whereby soft wares such as Google search were developed as searching engines to simplify access to those electronic materials. However, it is worth noting that the uses of electronic resources go hand in hand with ICT knowledge. Therefore, users of electronic journals should have knowledge on how to access those resources through computers and related devices. This competency enables learners' access the journals and e-books through their computers or other devices (Tsakonas \& Papatheodorou, 2006).

Studies on utilization of electronic resources by University students reveal that there is a growing interest among users and that these resources provide updated content compared to nonelectronic material resources. For instance, in India, younger University students like those studied from Assam University were intensively using electronic resources in their studies as well as social lives (Devi \& Roy, 2012). Similarly, in Indian Institute of Technology, Garg and Tamrakar (2014) found that utilization of electronic resources was common not only among students but also among staff with the two categories discarding non-electronic materials. Consequently, Owalebi, et al., (2016) in a study conducted in Ibadan University, Nigeria, noted the importance of electronic resources in university teaching and learning as it slowly replaced the use printed materials. These resources were commonly used in writing assignments, course works, projects as well as normal registration and personal purposes.

In developing countries like Tanzania, Kenya, Nigeria and others, there is great change of technology especially in ICT. Most of the higher education institutions started to offer the ICT courses that have increased the use of electronic resources. Most of the old libraries in developing countries became useless since students are more interested in the use of the internet to access electronic journals (Olaniran, Duma \& Nzima, 2017). In fact, South Africa was among the first African Countries to offer Open and Distance Learning (ODL) program for ODL based pre-service teacher trainees, a program that involves massive use of electronic resources (Olaniran, et al., 2017). It is evident from Olaniran et.al that the electronic resources are available in Nigerian higher learning institutions and students are willing to use them. However, most students are unable to access the resources. Another study conducted in the Great Zimbabwe University revealed that electronic resources were available but their utilization was limited by internet challenges, interruption or total lack of electricity and poor knowledge on the use of Information Technology (Mawere \& Sai, 2018).

In Tanzania, a study by Mahenge and Sanga (2016) on the use of ICT for e-learning in higher institutions revealed that the transition rate from using material resources to electronic resources was impressive evidenced by $85 \%$ of the university students owning computers while only $15 \%$ of the students did not. In addition, they noted that many universities in Tanzania allowed their students to access free wireless networks at the university although the internet access was very low due to population and poor infrastructures (Mahenge \& Sanga, 2016). Despite the efforts done by some higher learning institutions in installation of ICT facilities, the access to electronic resources in higher learning institutions remains limited as some users prefer the outdated hardcopy material resources in the libraries (Nkebukwa,2016; Mawere \& Sanga, 2016).

The basis of this study is therefore to investigate the accessibility of electronic resources among students in higher learning institutions in Mwanza city, Tanzania. The study sought to answer the following specific research questions:

1. Do the available infrastructures ensure accessibility to electronic learning resources in higher learning institutions in Mwanza City?

2. Does financial capacity of students in higher learning institutions accord the opportunity to access the electronically stored materials for learning purposes in Mwanza City?

3. Are Students in higher learning institutions equipped with skills and knowledge on accessing electronic learning resources in Mwanza City?

\section{Related Literature and Studies}

This section presents the theoretical and empirical literature that informed the study.

\section{Theoretical Literature}

The study employed the utilization theory since the focus of the study is accessibility of electronic learning resources in higher institutions. The theory which was developed by Sarkar in 1959 proposes the prerequisites for better utilization of learning

\section{East African Journal of Education and Social Sciences (EAJESS) 1(3)12-19}


resources deposited in an electronic form and how they can be exploited by students in conducting their studies especially in colleges and universities. Sarkar (1959) argues that although the learning materials may be available, it does not mean that the materials are being utilized. The theory is relevant to this study because it acknowledges that the presence of electronic learning resources should go together with the use of those resources.

Nkebukwa (2016) shows that although the higher learning institutions like College of Business Education (CBE) have electronic resources, still there are challenges such as physical buildings equipped with internet connectivity, ICT equipment as well as relevant software and training opportunities that are not adequately supportive to learners. It is therefore evident that the availability of electronic resources is not the end in itself. Establishment of adequate infrastructure including internet connectivity, electricity connection, physical space, relevant software and training for capacity building are critical elements for accessibility of electronic learning resources in higher learning institutions.

\section{Empirical Literature Review}

Accessibility to electronic learning resources is a pre-requisite to successful teaching and learning in a University. Outside Africa, various studies have shown that access to and utilization of electronic resources to support learning in universities requires proper infrastructure. For instance, Soni, Gupta and Shrivastava (2018) conducted a study on awareness and usage of electronic resources among LIS scholars of Jiwaji University in India by using a survey method. Their findings showed that there is a significant relationship between the infrastructure and accessibility to electronic resources. The findings further showed that only few LIS research scholars reported that there was a shortage of computers, network problems and absence of materials. From the study, $70 \%$ of respondents reported that there were no infrastructural problems when relating to the accessibility of electronic resources.

Yamson et al. (2018) conducted a study on electronic versus print resources: a survey of perception, usage and preferences among central university undergraduate students in Ghana. Using survey method, they found that most of the university infrastructures were not supportive enough to allow students to access the electronic resources. However, the old university libraries contained so many books that influenced learners to prefer printed books from the libraries. This shows that the use of electronic resources in African universities is different from developed countries like India (Soni, Gupta \& Shrivastava, 2018).

Similarly, Madondo, Sithole and Chisita (2017) conducted a study on the use of electronic information resources by undergraduate students in the faculty of management and administration at the Africa University in Zimbabwe by using qualitative method and came up with the findings that the infrastructures were not adequate to support effective accessibility of electronic resources. Most of the students in the University encountered network problems in accessing electronic resources. This seems to support the findings in Ghana that most of the African universities are in the transition rates of transferring learners from printed resources to electronic resources through construction of infrastructures that will allow effective use of electronic resources. On the contrary, Adeleke and Nwalo (2017) in their study on the availability, use and constraints to use of electronic information resources by postgraduate students at the University of Ibadan in Nigeria, by using descriptive survey research design, observed that there were no problems associated with financial capacity since all the facilities and services were offered by the universities. The post graduate students were allowed to access the electronic resources from the university libraries at no cost.

Kumari (2015) conducted a study in India procurement, management and use of e-resource in current library trends: common issues. From the findings of the study, the issue of explosion of information and managing electronic resources was a big challenge to many electronic users. The study established that there is no enough training to library users on how they can access the required information in a simple way. Most of library users experienced complications on how to get the right information at the right time because of lack of skills and knowledge on ICT and computer uses.

From the reviewed literature, different studies have been done by different scholars especially in India, Nigeria and Tanzania on accessibility and utilization of electronic resources. The findings from previous studies emphasize the role of infrastructure and training of users particularly the library staff (Kumari, 2015; Adeleke \& Nwalo, 2017). This study focused on students in higher learning institutions. 
Secondly, studies conducted in Tanzania were in Dar es Salaam, Morogoro and Arusha which are distinct Districts (Juventus \& Jeje, 2016; Kumari, 2015). The researcher therefore sought to fill the geographical gap by focusing the study in Mwanza City.

\section{Research Methodology}

This section presents the research design, population and sampling techniques, data collection and data analysis procedures.

\section{Research Design}

The study employed a mixed research approach and a convergent parallel research design. Creswell (2014) defines a mixed research design as an approach where a researcher collects both the quantitative and qualitative data simultaneously or concurrently. The purpose of choosing this design was to get additional information from secondary sources and support the primary sources of data so as to build on the strength of both qualitative and quantitative approaches. On the other hand, according to Creswell and Pablo-Clark (2011), a convergent parallel design is the mixed research design that enables the researcher to collect the quantitative and qualitative data at the same time in the same phase of the research process, weigh the methods equally, analyze the two components independently and interpret the results together. Through this method, the researcher was able to collect and analyze both qualitative and quantitative data that were different from other studies that used single research designs.

\section{Population and Sampling Techniques}

The target population of this study included 300 instructors/lecturers, 15,000 students, 150 librarians and 50 ICT experts which brings the total of 15,500. The researcher visited each of three institutions and used stratified sampling to select students from these institutions whereby the researcher grouped students based on their year of study. For example, first year, second year and third year students were selected regardless of the course of specialization and then some of them were selected to construct the sample by using simple random sampling to get 377 students. The study used this method because it gives the chance to each of the respondents to be included in the study without bias. Simple random sampling was used to select the sample of 8 lecturers/instructors whereby the researcher developed a list of names of all instructors in the institutions that were investigated and assigned numbers to those names then put the numbers in the container and selected some randomly until the required sample size was reached. Purposive sampling was used to select some librarians and ICT experts from the selected institutions (Raune, 2006).

\section{Validity and Reliability}

The researcher obtained the validity through expert judgment whereby some experts looked into the research questions along with the instruments and gave inputs before the instruments were used for data collection. In addition, the researcher tested the reliability of the research instruments through test re-test method which showed that the instruments were consistent since the reliability coefficient results of the research instruments were 0.7 Cronbach's Alpha in each time (Kumar, 2011).

\section{Statistical Treatment of Data}

Qualitative data obtained from structured interview and open ended questions were analyzed and presented based on content analysis. The data was then presented through reporting and explaining what the respondents were saying. On the other hand, quantitative data obtained from closed ended questionnaires were coded using SPSS and analyzed using descriptive statistics (Raune, 2006).

\section{Analysis and Results}

The study sought to investigate the accessibility to electronic resources by students in three higher learning institutions in Mwanza City. Specifically, the researchers sought to find out whether available infrastructures ensure accessibility to electronic learning resources in higher learning institutions in Mwanza City; whether the financial capacity of students in higher learning institutions accorded them the opportunity to access the electronically stored materials for learning purposes and whether the students in higher learning institutions were equipped with skills and knowledge on accessibility to electronic stored learning materials.

Research Question 1: Do the available infrastructures ensure accessibility of electronic learning resources in higher learning institutions in Mwanza City?

With regard to this question, the findings that emanated from students' responses are presented in Table 1. From the table, 7.2 percent of the students and 12.5 percent of lecturers agreed that available infrastructure ensured accessibility to electronic learning resources respectively while 92.8 percent of students and 87.5 percent of lecturer disagreed with the statement. This implies that 
higher learning institutions did not have adequate infrastructure for electronic learning resources not only for students but also for lecturers. Likewise, the qualitative data indicated that the major infrastructural challenges faced include electricity problem, shortage of computers and network problems. These findings show that there is poor accessibility of electronic learning resources available in higher learning institutions in Mwanza. If students and lecturers cannot access these resources, then they are not useful to them. While universities spend a lot of funds every financial year to subscribe to electronic resources such as e-books and online journals, it is a pity that they are only accessed by a small number of lecturers and students. The findings are similar to those of the study by Soni, Gupta and Shrivastava (2018) who looked at the relationship between availability of infrastructure and accessibility to electronic learning resources. Their study focused on looking at factors that affected accessibility of electronic learning materials and found that learners had a lot of difficulties accessing electronic materials and this affected

studies.

Table 1: Accessibility to Infrastructure for Electronic Learning Resources

\begin{tabular}{lllll}
\hline ITEM & STUDENTS & \multicolumn{3}{c}{ LECTURERS } \\
\hline RESPONSE & Frequency & Percent & Frequency & Percent \\
Yes & 27 & 7.2 & 1 & 12.5 \\
No & 350 & 92.8 & 7 & 87.5 \\
Total & 377 & 100.0 & 8 & 100.0 \\
\hline
\end{tabular}

Table 2: Accessibility of Financial Resources for Electronic Learning Resources

\begin{tabular}{llll}
\hline S/N & Category & Frequency & Percent (\%) \\
\hline 1. & Yes & 75 & 20 \\
2. & No & 302 & 80 \\
& Total & 377 & 100 \\
\hline
\end{tabular}

Furthermore, this study notably shades more light by identifying the specific challenges which students and lecturers face in their attempt to access the electronic resources. This includes frequent power blackouts which are common in the city of Mwanza. In addition to power blackouts, higher learning institutions in Mwanza had poor internet connectivity. This made it even more difficult for students wishing to access some of the online journals and even books.

On the other hand, the study by Soni et al. was conducted outside Tanzania. Tanzania is a developing country and it has unique problems which are faced by higher learning institutions and therefore, there is a need to establish these problems so that they can be dealt with by crafting relevant policies and implementing them. Higher learning institutions are relied upon by the society to create and disseminate knowledge; this will not happen if resources required by faculty to enable them facilitate learning are not there. Lack of reading materials is also likely to hinder learning which is likely to affect a student's ability to be creative and innovative. Lack of innovativeness by students will result in higher learning institutions producing half-baked graduates who might not contribute to social economic development of the country. Therefore, there is a need for administrators in higher learning institutions to ensure that electronic learning materials are available in the libraries and are accessible. They need to acquire more computers for their libraries as many students cannot afford laptops and even smart phones which could be used to access websites and even store some of the electronic materials.

Research Question 2: Does the financial capacity of students in higher learning institutions accord the opportunity to access the electronically stored materials for learning in Mwanza City?

The findings to this question are presented in Table 2. From the table, 20 percent of the respondents had adequate financial resources to enable them to access electronic learning resources while 80 percent did not have enough financial resources. Clearly, a minority of the respondents did have the financial capacity to access the resources. It is significant to note that a large number of students cannot access electronic resources available in the university libraries because they do not have enough financial muscles. Considering that the university does not have adequate computers where each learner would go, sit and surf the net or 
download some materials to read later, then it is expected that the students have their own laptops to enable them access the electronic resources. Students who cannot afford their own laptops and iPod's which are very costly will have no any other option but watch from a distance. Even if they had their own smart phones, they need internet bundles to help them access the websites where these materials are hosted.

Since the higher learning institutions internet is weak, unreliable and sometimes not available, students use internet supplied by mobile service providers such as Vodacom, Tigo or Airtel. Bundles are costly and for the three to four years which a student is expected to stay at the higher learning institutions, they will have to spend a lot of money. Bearing in mind that majority of the students come from very poor backgrounds, they are not able to buy the internet bundles and as the result, they end up suffering silently. In fact, they are denied an opportunity to access current reading materials to enable them to effectively prepare for the world of work and for their examinations. This may make students to be insecure and ready to deploy unethical means to pass their examinations such as cheating. In contrast, those who coming from well to do families have the opportunity to own smart phones, expensive laptops and buy internet bundles with ease. This creates disparities between students and it is not a good practice in higher education. Facilities should therefore be available for all students equally and no student should feel disadvantaged; for this is likely to affect curriculum implementation in institutions of higher learning.

While some people in industry have been complaining that many graduates from colleges and universities cannot perform once they hired, this could be blamed on poor acquisition of necessary competencies due to poor accessibility to electronic learning resources due lack of funds. Equally, qualitative data pointed a picture of students who are suffering and no one seems to be listening to them. Notably, those interviewed indicated that students are sometimes forced to photocopy some materials at a very high cost while they could access the same materials freely from the library if they had smart phones or even laptops.

Above all, this is not the only study that has looked into how inadequate funds by students affect their ability to access electronic learning materials such as those available in the library. A study by Adeleke and Nwalo (2017) paints a contrasting picture of the situation in Nigeria. They observe that most of the higher learning institutions in Nigeria have enough facilities in their libraries to enable students' access electronic library resources and students need not to depend on their own laptops or desktops to access the electronic materials in the library. Considering that Nigeria is a developing country like Tanzania and it has prioritized equipping higher learning institutions libraries with adequate computers and reliable network and supplying stand by generators, possibly administrators in Tanzania higher learning institutions should borrow a leaf from them and do the same so as to help learners who are currently experiencing challenges in accessing library resources. This will make learning effective in higher learning institutions, then, contribute to realization of objectives of institutions of higher learning.

Research Question 3: Are students in higher learning institutions equipped with skills and knowledge for accessibility of electronically stored learning materials in Mwanza City?

The results to this research question are shown in table 3 . From the table 3 , the findings indicated that 40 percent of the respondents had the accessibility skills and knowledge for electronic learning material while 60 percent did not have. These findings show that a majority of the students in higher learning institutions under investigation did not have appropriate knowledge and skills that would enable them access electronic learning resources. This finding is similar to that of Adeleke and Nwalo (2017) who found that in Nigeria, library users lacked the requisite knowledge and skills for accessing and exploitation of electronic learning resources.

Table 3: Skills and Knowledge for Electronic Learning Resources

\begin{tabular}{llll}
\hline S/N & Category & Frequency & Percent (\%) \\
\hline 1. & Yes & 151 & 40 \\
2. & No & 226 & 60 \\
& Total & 377 & 100 \\
\hline
\end{tabular}


Consequently, results from interviews showed that not only students in higher learning institutions were having problems in exploring stored electronic resources but also some of the lecturers in some of the institutions were lacking skills and knowledge. This was similar to the findings by Goodluck and George (2014) who argue that although the university has established the electronic resources in the university library, still not only students but also some lecturers lacked skills and knowledge in accessing and utilizing electronic resources.

\section{Conclusions and Recommendations}

This part gives conclusions and corresponding recommendations of the study as informed by the study findings.

\section{Conclusions of the Study}

While the first question of the study was to determine whether the available infrastructures ensure accessibility of electronic learning resources in higher learning institutions in Mwanza City, the study concludes that most institutions did not have infrastructures such as computer laboratories, electricity and reliable internet for accessibility to electronic learning resources by students and lecturers in higher learning institutions.

The second question was whether the financial capacity of students in higher learning institutions accords the opportunity to access the electronically stored materials for learning purposes. From the study findings, majority of the students in higher learning institutions did not have the financial capacity to access electronic learning resources.

Finally, the study sought to establish whether the students in higher learning institutions are equipped with knowledge and skills for accessibility of electronic stored learning materials. It is concluded that majority of the students in higher learning institutions lacked accessibility knowledge and skills. As a result, the study maintains that students in higher learning institutions were unable to use computers in accessing electronic stored resources due to lack of computer knowledge and skills.

\section{Recommendations}

Based on the first conclusion, the study recommends that the higher learning institutions should work together with the government and other stakeholders to finance the establishment of adequate infrastructure to enable accessibility of electronic learning resources to students since we live in the age of science and technology.

Based on the second conclusion, it is recommended that parents and sponsors should provide adequate financial resources to the students in higher learning institutions to enable them secure electronic devices and funds to buy internet bundles where free internet is not available for accessing electronic learning resources. Seminars need to be conducted for students to prioritize academic matters when they receive funds from sponsors.

Finally, based on the third conclusion, the study recommends that learning institutions should come up with initiatives to help their students to acquire basic skills in the use of computers. This will enable them to easily access stored resources. Collective initiatives should be put in place to make sure that ICT subject is taught from primary schools to higher learning institutions so as to effectively embrace global challenges mainly attributed to advancement in computer technology.

\section{Reference}

Adeleke, D. S. \& Nwalo, K. I. N. (2017). Availability, Use and Constraints to Use of Electronic Information Resources by Postgraduates Students at the University of Ibadan. International Journal of Knowledge Content Development \& Technology, 7(4), 51-69.

Creswell, J. W., \& Plano Clark, V. L. (2011). Designing and conducting mixed methods research. London, SAGE publication.Inc.

Creswell, W. J. (2014). Research design, quantitative, qualitative, and mixed method approaches, $\left(4^{\text {th }}\right.$ ed.). Los Angeles: SAGE.

Devi, C. B and Roy N. R. (2012).Internet Use among University Students: A Case Study of Assam University Silchar. A Journal of Humanities and Social Sciences, 1(2), 183- 202.

Garg, R. G and Tamrakar A. K. (2014). Utilization of Electronic-resources by the postgraduate students, research scholars and faculty members of Indian Institute of Technology, Kharagpur. Department of Library and Information Science, 3(2), $75-85$.

Goodluck, M. E \& George, B. E. (2014). Barriers of Using Internet Resources in Higher Learning 
Institutions: A Case of Mzumbe University in Morogoro Region in Tanzania. Journal of Information and Knowledge Management, $4(8), 64-72$.

Juventus, L. L \& Jeje, K. (2016). Factors Influencing Academic Library Use in Tanzania: A Multiple Regression Analysis. Journal of Library and Information Studies, 14(2), 1-20.

Kumar, R. (2011). Research methodology, a step by step guide for beginners. London, SAGE publications Ltd.

Kumari, P. (2015). Procurement, Management and Use of E-Resource in Current Library Trends: Common Issues. International Journal of Digital Library Services, 5(2), 150 159.

Madondo, T., Sithole, N., \& Chisita, C. T. (2017). Use of Electronic Information Resources by Undergraduate Students in the Faculty of Management and Administration at

Africa University, Mutare, Zimbabwe. Asian Research Journal of Arts \& Social Sciences, 2(2), 1-12.

Mahenge, M. P. J. \& Sanga, C. (2016). ICT for Elearning in three Higher Education Institutions in Tanzania. Knowledge, Management \& E-learning, 8(1), 200-212.

Mawere, T. and Sai, K. O. S. (2018). An investigation on E-resource Utilization among University Students in a Developing Country: A case of Great Zimbabwe University. South African Journal of Information Management, 20(1), 1- 7.

Nkebukwa, L. L. (2016). Status on Usage of Electronic-Resources by Students at the College of Business Education. Business Education Journal, 1 (2), 1 - 13.
Olaniran O, Duma M.A.N \&Nzima, D.R. (2017). Assessing the Utilization Level of $E$ Learning Resources among ODL Based Pre-Service Teacher Trainees. The Electronic Journal of e-Learning, 15(5), 385 - 395.

Olaniran, D. \& Nzima, M. (2017). Assessing the Utilization Level of E-Learning Resources among ODL Based Pre-Service Teacher Trainees. The Electronic Journal of eLearning, 15 (5), 385-395, retrieved from www.ejel.org

Owolabi, S., Idowu, O. A., Okocha, F., \& Ogundare, A. O. (2016). Utilization of Electronic Information Resources by Undergraduate Students of University of Ibadan: A Case Study of Social Sciences and Education. Journal of Education and Practice, 7(13), 30 - 36. Retrieved from www.iiste.org

Raune, J. M. (2006). Essentials of Research Methods: A Guide to Social Science Research. India, Blackwell Publishing Ltd.

Soni, N. K., Gupta, K. K., \& Shrivastava, P. (2018). Awareness and Usage of Electronic Resources among LIS Scholars of Jiwaji University, Gwalior: A Survey. Journal of Library \& Information Technology, 38 (1), 56 -62 .

Tsakonas, L \& Papatheodorou, M. (2006). Analyzing and evaluating usefulness and usability Turkey: the results of a survey. Journal of Academic Librarianship, 34 (4), 239-47.

Yamson, G. C., Appiah, A. B \& Tsegah, M. (2018). Electronic vs. Print Resources: A Survey of Perception, Usage and Preferences among Central University Undergraduate Students. European Scientific Journal, 14 (7), 2 